\title{
CORRIGENDUM
}

\section{Six-year follow-up of patients receiving imatinib for the first-line treatment of chronic myeloid leukemia}

A Hochhaus, SG O’Brien, F Guilhot, BJ Druker, S Branford, L Foroni, JM Goldman, MC Müller, JP Radich, M Rudoltz, M Mone, I Gathmann, TP Hughes and RA Larson for the IRIS Investigators

Leukemia (2010) 24, 1102; doi:10.1038/leu.2010.71

Correction to: Leukemia (2009) 23, 1054-1061; doi:10.1038/ leu.2009.38

Since the publication of this paper, the authors have noticed that the name of an Investigator from the IRIS trial has been omitted from the Appendix. The details of this Investigator are shown below.

Italy_Università degli Studi di Firenze, Florence: V Santini. The authors apologize for any inconvenience caused. 